\title{
Environmental geology and cooperation with developing countries
}

The destruction of the environment as a direct result of poverty is increasingly threatening the very basis of the existence of thousands of millions of people throughout the world. This trend must not be allowed to continue unchecked. The aims of environmental geology in Germany's Technical Cooperation projects focus on the requirement to "protect the environment by environmental planning and environmentally compatible resources management." The direct relationship between poverty and the destruction of the environment makes it important to integrate environmental geology projects into development aid programs that combat poverty as a basic strategy.

\section{Preface}

The unchecked population growth in the developing countries has not been alone in leading to an environmental and development crisis affecting the whole human race. Increasing industrialization in the industrial countries and the exploitation of the world's natural resources also have contributed to this crisis.

In comparison with other scientific disciplines such as chemistry, biology, medicine, and meteorology, the importance of the geosciences in environmental protection and in solving environmental problems has hardly been recognized by the general public. However, the causes of environmental problems can be understood only by having knowledge of geological relationships and geological processes. Therefore, these must be taken into account when planning and carrying out remedial measures that are designed to protect the environment.

Because both the investigation and solution of environmental problems involve the knowledge of numerous geoscientific disciplines that are interrelated and must be integrated effectively, this is referred to often as environmental geology. Naturally, because this includes a wide range of related disciplines, the term "environmental geology" and the field it covers both are open to different interpretations. In this article, we do not propose to define the term but to give an account of the many disciplines covered by the geosciences, their fields of application in furthering environmental protection and development, and their chief objectives. This account follows the basic principles of the Federal German Government's development policy as it has been applied to German Technical Cooperation projects in the field designated "environment and development."

We hope to demonstrate to political decision makers that environmental geology is the vehicle by which much environmental damage can be avoided or remedied.

\section{Poverty, population explosion, and destruction of the environment}

Poverty, population explosion, and destruction of the environment are elements of a vicious circle in which numerous developing countries are caught and from which they are unable to escape without aid. Although the governmental officials of these countries know quite well that the protection of their environment is a highly important objective of development policy, their constant fight against poverty leaves them little freedom of action. They mainly lack the financial means and technical know-how, but they also may lack the necessary enlightenment and information.

In numerous developing countries, the ecological balance and future outlook give cause for alarm, as seen in these examples:

- About 1 billion people already are living below the poverty line, but the increase in the world's population (from the current 5 billion to $8-10$ billion in 2020 ) will take place almost exclusively in the developing countries.

- Even now, about 1 billion people are suffering from a critical shortage of energy. However, the demand for primary energy will increase rapidly during the next 30 years.

- For about 2 billion human beings, firewood is still the most important source of energy. As a result, the environmental damage caused by the collecting of firewood is serious (for example, erosion and the reduction in the rate of groundwater recharge).

- Annually, more than $170,000 \mathrm{~km}^{2}$ of tropical rain forest (corresponding to approximately one-half the area of Germany) is destroyed by burning the forest and by the felling of trees. If this rate of destruction is maintained, the tropical rain forests will have disappeared by the year 2000 , except for a few small areas in South America, central Africa, and Southeast Asia.

- In the developing countries alone, $200,000 \mathrm{~km}^{2}$ of arable land is destroyed annually by soil erosion.

- The annual global increase in the area covered by deserts amounts to $60,000 \mathrm{~km}^{2}$.

- A shortage of drinking water and polluted drinking water threaten the health of about 2 billion people.

- In many developing countries, the living conditions are becoming more and more disastrous in the expanding, large conurbations (megacities). In the year 2000 , about 2 billion people will live in the cities in these countries.

\section{Contribution of environmental geology to environmental protection and development}

The ultimate causes of poverty, population explosion, and destruction of the environment are very complex. Therefore, the measures to 


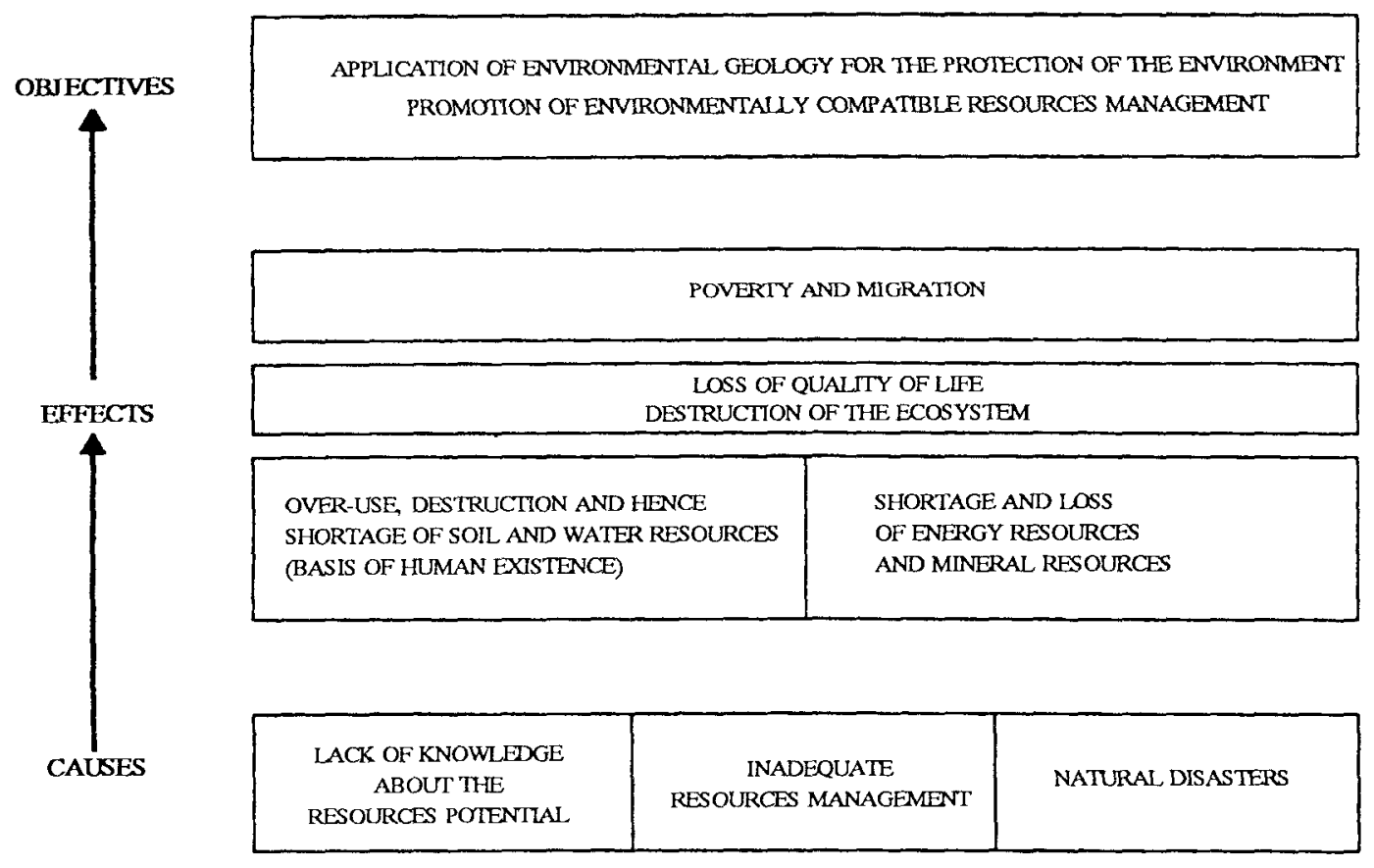

Figure 1. - The value of environmental geology in both the protection of the environment and the fight against poverty.

reduce or remove these negative factors must be initiated at as many levels as possible. Environmental protection projects should aim not only at solving specific problems but also should have a broad, beneficial impact and thus should contribute directly to the fight against poverty. To guarantee that the effect is lasting, these projects should be integrated into comprehensive development strategies as well. In order to be effective, environmental protection should encompass the investigation and assessment of natural resources, as well as the study of the processes that have an impact on the environment. Moreover, the results obtained should be used for environmental planning, resources protection, and resources management. However, ecological objectives cannot be achieved without expert knowledge in the field of environmental geology and without applying well-established and reliable methods in the investigation stage (fig. 1).

As a first step, the specialist in environmental geology makes an inventory of the potential of the natural resources of a region and investigates the reciprocal effects of human activities and the Earth. The specialist also examines the causes and consequences of natural disasters. One should not lose sight of the fact that these additionally may cause considerable damage and destruction to the environment (for example, earthquakes, volcanic eruptions, landslides, and floods).

In order to deal with the complexity of the processes and reciprocal effects in nature, environmental geology depends on the expert knowledge, experience, and methods of a whole spectrum of disciplines (fig. 2). The geologist who specializes in environmental geology is capable of recommending preventive, protective, and rehabilitative measures within the framework of active environmental protection. Such an individual also can provide basic data for planning resources management in such a way that the environment is protected and development is encouraged.

The most important tasks and objectives of environmental geology in German Technical Cooperation projects are the following (fig. 3):
- Making inventories, assessments, and environmentally compatible utilization and protection of the resources of water and soil

- Identifying sites for waste disposal

- Making inventories, assessments, and environmentally compatible utilization of energy and mineral resources (including renewable forms of energy such as, for example, hydroelectric and geothermal power)

- Forecasting natural disasters, especially earthquakes, volcanic eruptions, landslides, and floods, and minimizing the potential of damage caused by them

- Forecasting, assessing, limiting, and reversing environmental changes caused by human impact on nature (environmental impact assessment)

- Basic and advanced training of personnel from developing countries and introducing them to problems related to environmental geology, as well as the application of geological data to land-use and regional planning (environmental planning)

The German Federal Institute for Geosciences and Natural Resources (BGR), following its mandate, has been working on Technical Cooperation projects with developing countries for more than 30 years on behalf of the Federal German Government. The BGR possesses all the necessary requirements for independently carrying out to a high standard interdisciplinary studies on complex environmental problems. The BGR analyzes these problems and points out possible ways of solving them. A good example of how BGR's expert potential can be applied is shown by considering the strategy adopted for the project "Megacities - environmental geology and its applications in land-use and regional planning" (fig. 4).

Technical Cooperation projects involving problems related to environmental geology have gained steadily in importance as an essential part of development policy. The BGR is, therefore, increasing its engagement in this field and regards it as a priority task. 


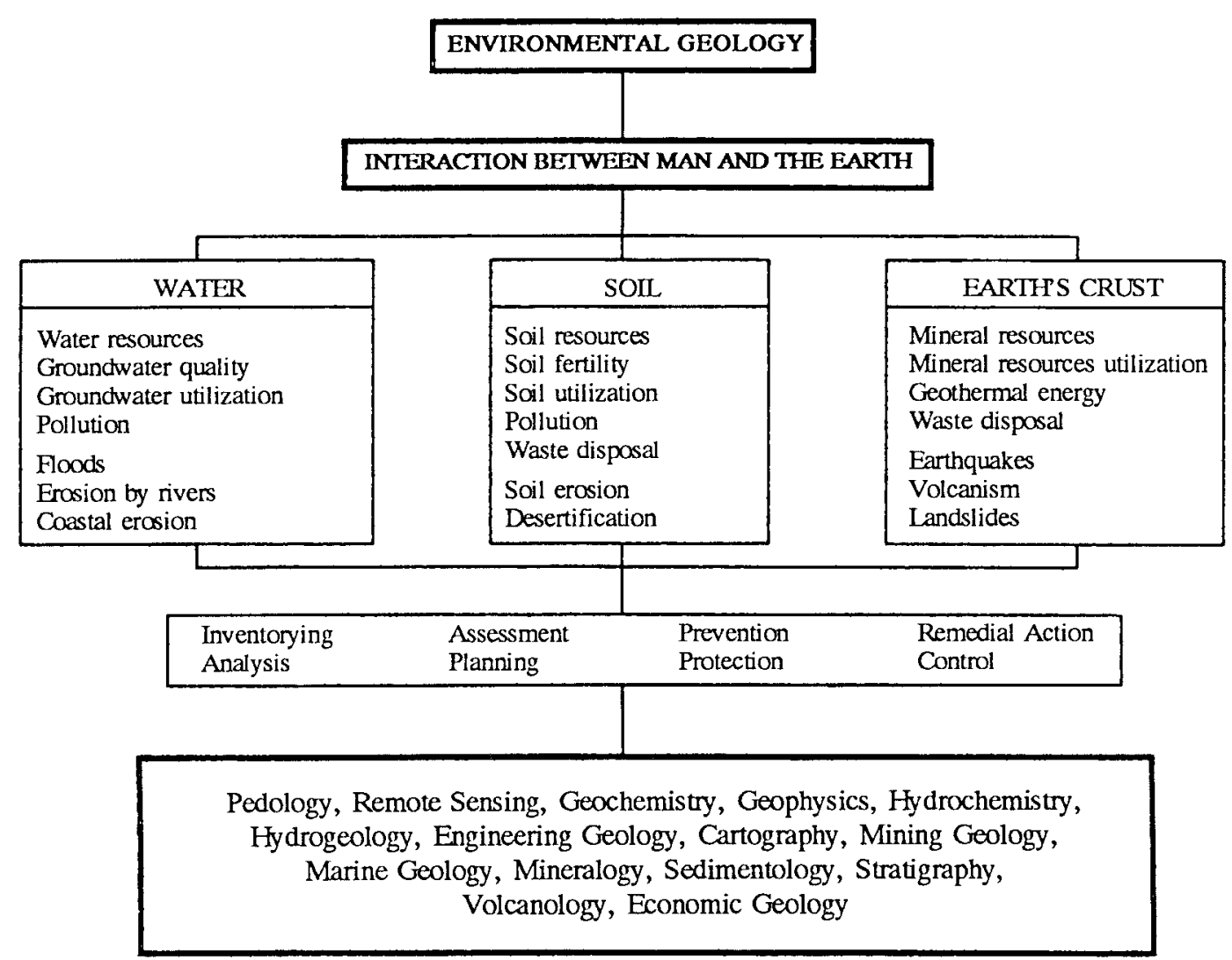

Figure 2.-The project fields, scope of activities, and relevant disciplines of environmental geology.

\section{Acknowledgments}

This paper was written with the help of the German BGR's Technical Cooperation Group, which is an interdisciplinary group of experts from both scientific and technical fields. We are most indebted to them for their enthusiasm and support: H. Aust, H. Bender, W. Eberle, W. Eckelmann, S. Grätsch, R. Hoffmann, K. Krampe, W. Kruck, H. Mollat, C. Müller, C. Neumann-Redlin, B. Schwerdtfeger, B. Söfner, W. Struckmeier, H.-H. Voss, W. Wagner, and K. Zimmermann. The figures presented are based on planning schemes that are used normally for development aid projects.

\section{References}

Federal Ministry for Economic Cooperation and Development (BMZ), 1986 The basic principles of the Federal Government's development policy: Bonn, Germany, Federal Ministry for Economic Cooperation and Development, $44 \mathrm{p}$.

-1989, Environment and development: Bonn, Germany, Federal Ministry for Economic Cooperation and Development, $23 \mathrm{p}$.

German Agency for Technical Cooperation (GTZ), 1988, ZOPP: Objectivesoriented project planning, an introduction to the method: Eschborn, Germany, German Agency for Technical Cooperation, 31 p. $\square$ 


\section{OBJECTIVES}

GEOLOGY, NATURAL RISK FACTORS, PRESENT AND FUTURE CLAIMS ON NATURAL RESOURCES, AS WELL AS THEIR ENVIRONMENTAL IMPACT, ARE IDENTIFIED AND ANALYZED FOR THEIR SIGNIFICANCE TO LAND-USE AND REGIONAL PLANNING

STRATEGIC PLANS FOR RESOURCES MANAGEMENT ARE SET UP QUALIFIED NATIONALS HOLD RESPONSIBLE POSITIONS

FIELDS OF ACTIVITY
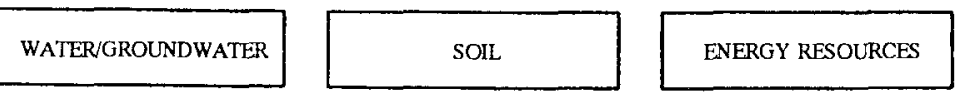

WATER RESOURCES
quantified
WATER QUALITY
assessed and regularly
monitored
GROUNDWATER
WTIHDRAWAL
compatible with the
environment
GROUNDWATER
PROTECIION AREAS
delineated
CONTAMINATION OF
GROUNDWATER
roduced to a minimum

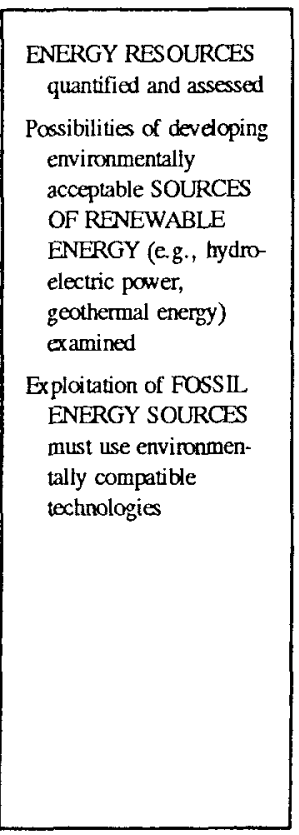

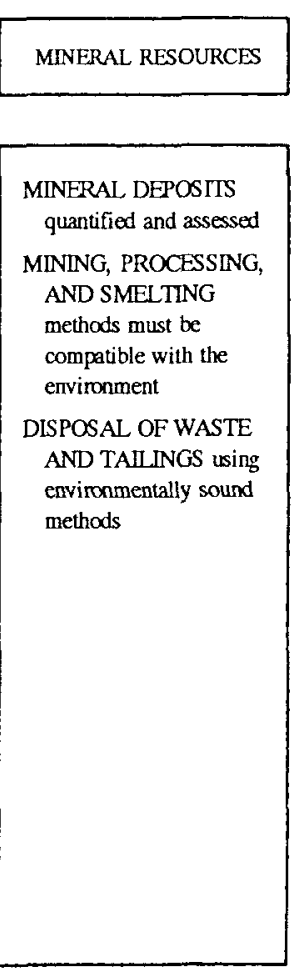

NATURAL DISASTERS

Seismic risks
(EARTHQUAKE
HAZARDS) analyzed
and conclusions drawn
Potential risk of
VOLCANIC
ERUPTIONS assessed,
and measures taken to
give carty warning and
mitigate the effects
Causes of FLOODS
analyzed, and preventive
measures taken
Potential of the risk of
MASS MOVEMENT
(e.g., landslides)
determined, and
recommendations neoded
EROSION PROCESSES
(coasts, rivers, slopes)
investigated, and
protective/preventive
measures taken

Figure 3. - Tasks and objectives of environmental geology in German Technical Cooperation projects with developing countries.

\section{OBJECTIVES}

\begin{tabular}{|c|}
\hline $\begin{array}{c}\text { Responsible utilization } \\
\text { of water resources }\end{array}$ \\
\hline
\end{tabular}

Controlled disposal
of waste and sewage

Land-use and regional planning

Guidelines issued and laws enacted

Authorities undertake efficient planning, monitoring, and supervision

\section{FIELDS OF ACTIVITY}

- Exploitable groundwater resources quantified
- Strategic plans for groundwater exploitation
drawn up
- Groundwater protection areas delineated
- Groundwater quality assessed and regularly
monitorcd

- The regional natural-resources potential (soil, water, mineral resources) quantified and assessed

- The hazard potential determined (e.g., landslides, earthquakes, anthropogenic impact)

- Engineering-geological data considered

- Land-use plans drawn up, priorities settled in case of conflicting interests

- Strategic plans for resources managenent prepared

Figure 4. - Strategy adopted for the use of environmental geology in land-use and regional planning in project on megacities. 

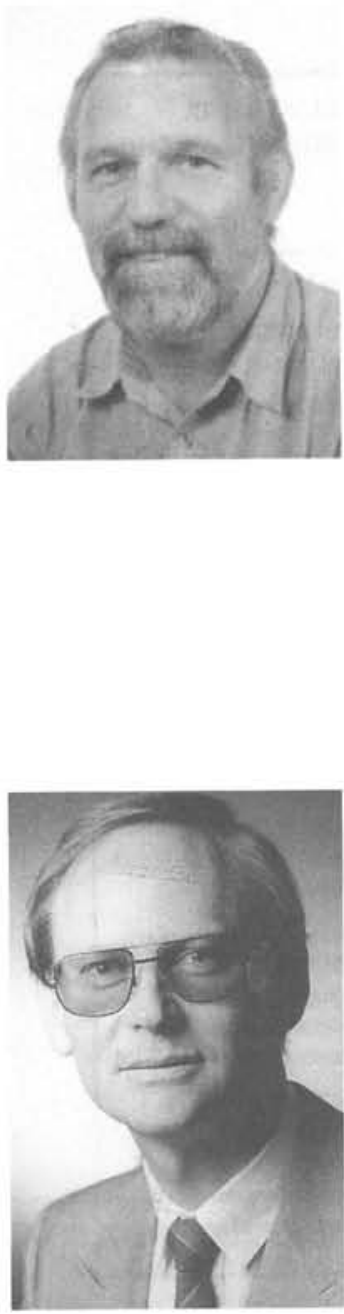

Dr. Michael Schmidt-Thomé (Head, Subdivision of International Cooperation, Bundesanstalt für Geowissenschaften und Rohstoffe (BGR)) was educated at the Universities of München and Würzburg, Germany. He has been in the service of the German Government since 1968 as an employee of BGR. For more than 10 years, he gathered international experience as a geologist and project manager in Technical Cooperation projects in Third World countries. His scientific work concentrated mainly on the evolution of the Gondwana continent, particularly Antarctica. He participated in three BGR Antarctic expeditions to northern Victoria Land. Since 1989, he has been Treasurer of the International Union of Geological Sciences.

Dr. Michael von Hoyer took his studies in geology and hydrogeology at the University of Tübingen, Germany. From 1971 to 1975, he worked as a hydrogeologist in South Africa and the Middle East in the field of groundwater exploration and development, where he specialized in drainage methods for water-logged and saline soils. He joined the BGR in 1976 and has been the leader of hydrogeology projects in several African countries in the semiarid and arid zones. His interests are directed toward the study of natural and artificial groundwater recharge, groundwater protection, and groundwater legislation.

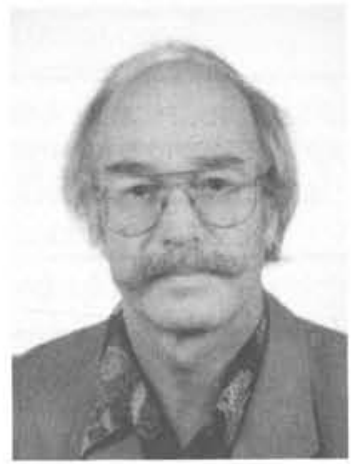

Dr. Jürgen Lietz received his professional education in the study of geology, geophysics, and mineralogy at the Universities of Köln and München, Germany. As a member of the petroleum-geological section of $B G R$, he worked for many years in Bangladesh and Burma within the framework of technical cooperation. In this work, he came into close contact with environment- and povertyrelated problems in developing countries.

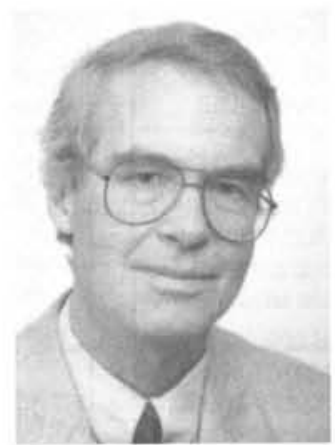

Dr. Walter Lorenz (BGR, Hannover) was educated at the University of Hamburg, Germany. He has been with the Federal Geological Survey since 1970 and became head of the Industrial Minerals and Rocks Section of BGR in 1979. He has acquired extensive international experience in this field through his work in many countries, especially in projects carried out within the framework of technical aid. 